\title{
THE IMPACT OF MANAGERIAL COMPETENCIES \\ ON THE MANAGERIAL PERFORMANCE \\ IN THE EDUCATIONAL SYSTEM
}

Cristina STAN

"Valahia" University of Targoviste

E-mail: krisciuca@yahoo.com

\begin{abstract}
The concept of competence in science education is in the midst of individual and collective performance. The complexity of the activity of running school has found a certain specific of its management that is materialized in two dimensions of the school activity: the variety of categories of staff and the interpersonal relationship, culture and work climate. All these result in the formation and development of a set of skills specific to the managerial field and necessary to the director of school in performing different roles sprung from this activity.
\end{abstract}

Keywords: management, competence, school manager, performance

JEL Classification: $\mathrm{F}_{19}, \mathrm{~B}_{19}, \mathrm{M}_{12}, \mathrm{M}_{54}$

\section{Introduction}

Over the years 1960 and 1970 studies tried to isolate and identify the factors which increase the efficiency of school and students' achievements. (Normand, 2006, p. 54) This movement generated a great number of instruments aimed at making educational systems. Edmonds (1979) identified the following five factors which, in his opinion, are correlated with effective school performance:

- a strong management and attention paid to the quality of education;

- great expectations concerning the performance of all students;

- emphasis on teaching basic subject (reading, writing, mathematics);

- frequent assessment and monitoring of students' progress;

About the same time, Rutter, Maugham and Mortimore discovered that the staff's attitude, their behaviour and the accent on the academic performance were the factors which influenced learning and that the pedagogical monitoring (effective monitoring practices) improved school results. (Rutter, Maugham, Mortimore \& Ouston, 1979, p. 58) Other factors such as class management makes students active in the learning process, a farm discipline and a good system of punishments and rewards improved the students' school final results. (Townsend, 2007, p. 43)

Starting with 1980, a new wave of research on effective schools tried to define their characteristics (Mortimore, Sammons, STOOL, Lewis, Ecob, 1988; Teddlie and Stringfield, 1993). In an analysis of 30 years of research on school 
performances, made primarily in Anglo-Saxon countries, and in Europe too, Sackney distinguished the characteristics and the groups of characteristics as factors which contribute positively to the effectiveness of school: (Sackney, 2007, p.170)

- Emphasis on students' learning, organizing time, priority given to basic skills;

- School climate, cohesion between teachers, consultation on the decisions, a pragmatic approach to problems;

- A strong culture of school organization, a clear vision of the mission, emphasis on the improve results;

- A high level of expectations and requests regarding the students and teachers;

- Intellectual stimulation;

- Rigorous monitoring of school progress and the results of the institute;

- A continuing concern for the training and professional development of the staff;

- The relations of partnership with parents and their involvement in school life.

An important instrument in ensuring the integration of the competency and performance is represented by the practical results obtained. School must be viewed as an organization that operates in education and formation in an open market of services. Its competitiveness consists in its capacity and speed of adaption to the needs of its social-economic environment.

The products offered by this on the market are the competences. Services provided by a school can be considered quality only if the satisfy the needs, requirements and expectations of their clients (firms, organizations, students) and of their partners (state, community, local public administration, parents). (Puchin, 2011, p. 134)

\section{Factors which influence managerial performance}

An important factor that influences the level of managerial performances is represented by the abilities of those who exercise management processes, of the managers respectively, but also of those who takes the decisions, meaning subalterns (performers).

Obviously, the decisive role has the manager no matter the position he has in the educational organization (director, deputy director, chief account, form-teacher, etc.). They influence fundamentally the managerial behaviour of this educational organization.

Competence can be approached in double aspect - on one hand as right competence attributed (named official authority) and on the other hand, as actual competence (personal authority).

If in terms of official authority, this acts at high levels at the level of management. 
In terms of personal authority, knowledge, professional skills and qualities must be find differently both at the level of those who have a management position and of those who have a performer position, while the knowledge, qualities and managerial skills are compulsory only for managers.

The level of quality management is decisive in reaching the objectives, in realizing the performance, or excellence in any type of collective action, no matter the given organization. The neglect of one management implementation of high quality generates a good part of the failure of the organization. What unites them is motivation.

Motivation is firstly taken into consideration, by the researchers, when they study the managerial performance predictors in other domains. (Harshman, 2009) The most important predictor of the managerial performance, as seen in many researches, seems to be the general mental ability. (Jackson, 2008)

General mental ability predicts the performance in basic tasks opposed to contextual performance. General mental ability influences the performance through the capacity and speed of accumulation of knowledge needed to perform. Intelligence tests cannot measure the typical variation for specific skills the same way as these specific skills are relevant to touch these goals.

Different non-cognitive traits seem to supply successfully the intelligence for different posts. One such trait seem to be general for the intelligence: conscientiousness - integrity but the size effect on the bases performance is considerably less than in the case of intelligence. Experience has an effect on performance, but it predicts it weak, while the complexity increases. Emotional intelligence has an influence on the contextual performance.

Moral intelligence has influence on company performance on medium and long term and it creates the movable between the individual performance and the organizational one, I mean on the given performance at the highest level, the impact of the organization on the social environment, the prestige of the business. (Kiel \& Lennick, 2005)

For performance prediction the most useful indicator is the competence. For intervention in order to improve the performance all competences can be used, but the most useful indicator is the learning competence.

The predictors of the managerial success are founded in a constellation in which some managers were better studied and other managers were barely understood and taken into account (moral and emotional intelligence), and others at all (systemic intelligence). All these predictors can be measured indirectly through the managerial competences.

\section{The managerial performance evaluation in the educational system}

New tendencies of the development of education involve promoting on managerial positions of well-prepared staff able to make qualitative changes in this domain. That is why to promote managers an evaluation is needed. In this context, the evaluation must be examined as a set of activities through which the obtained data are collected, organized and interpreted after some methods, techniques and 
instruments of evaluation were applied and elaborated according to the objectives and the evaluation type, according to the content and the chosen group work for the purpose of issuing a judge of value on which is based a certain decision in the educational plan. (Pâslaru, et al., 2005, p. 7)

Evaluation, in accordance with a quality education must have three distinct stages: measurement of training specialists offered by the university, analysis results and measures for improvement. (Molan, 2005, p. 59) The problem of a qualitative evaluation, in any stage, is of managerial nature obliging the manager of the educational institution to put into action certain mechanisms to ensure him that a certain quality level is reached.

A delicate issue is that of the leaders of the institutions of education evaluation

If it was less formal, we think many lacks of the managers would be discovered: a less quality formation because some of them continue to be selftaught in this domain distil and their own empirical experience, learning by trying and mistakes what is unacceptable when the educational system cannot and should not permit failures. (Cojocaru \& Slutu, 2007, p. 9)

Today, there is not any institutional initial and continuing training system for managers which would mean the professionalization of managerial activities and their training for all leadership structures of the educational system with positive repercussions for the changing of the attitudes, capacities and professional behaviour of the managers who lead certain institutions in the spirit of the modern management principles and methods.

The determination of an evaluation methodology of the manager's activity and the shift from appointment by delegation made by the inspectorate to the management contract system, unlimited in time is thought to be more efficient. In this case, his managerial contract must have clear performance criteria. Not less important is the using of a varied and gradual set of material-financial and moral rewards to recognize and reward the high managerial performances.

Mention should be made about the necessity of the managers' evaluation because the complexity of the managerial process, mainly its length and the diversity of its implications on the individual evolution, on group or social represent important arguments which require assessment and evaluation as a permanent activity.

Evaluation of managers must represent a measurement and comparison of the results activity, of the physical and intellectual potential, professional and managerial with the objectives and the occupied post requirements. (Nicolescu, et al., 1992, p. 301)

Evaluation of the manager in the context of the contemporary study context is dictated by the necessity related to the expressing and correct sizing of the objectives, both in their assuming and distribution. The orientation of the objectives, of the tasks that drive from these consist in the actions made by the manager to organize the work, to control the activity and evaluate the activity of the employee activity. 
Thus, a competent manager together with the managerial team will orient the activity focusing on clear purposes based on scientific principles with a decent expertise. In his activity, besides the function of organizer of the educational process, the manager will be an expert and a promoter of the values, this way improving all the segments of the educational institutions.

It is obvious the fact that the manager can be evaluated from different points of view, resulting a greater global number of criteria. For this reason, the scope of the evaluation needs to be mentioned. Evaluation of the performances is more extensive because it is based on results.

\section{Standards and ratings in the educational system} standards.

Once the evaluation criteria have been chosen, they are compared with the

Professional standards are defines through sets of competences and each competence from a certain level involves a performance criterion. Standards represent the desired level of the performances and, as a reference element in the results appreciation, enable highlighting of the degree the activities took place and the tasks were solved. Standard establish what and how well a person must do. They can be characterised by the following sizes:

- quantity (how much or how many)

- quality (how well or how complete)

- costs (related expenses)

- time (the moment the objective must be realized)

- use of resources (what equipment/ materials will be used)

- way of achieving (how the activities will be realized).

Standards are established before the activity starts, thus, all the people involved know what is expected from them. At the same time, it is important the meaning of the ratings used to appreciate the staff's performance be known. In general, five ratings are used: very good, good, satisfying, weak and very weak.

Evaluation is made by the direct leaders/managers, being the most useful type of evaluation. The direct leader has, formally, the necessary authority to realize the evaluation and reward the staff according to the obtained results. Moreover, these persons are able to observe the staff's performances and judge how these serve to the group and organisation's objectives.

In the managers' case, the process of their performances evaluation includes an annual report concerning every single performance. In drafting the report, more important is the evaluation of the results and not in the analysis of his behaviour.

\section{Methods of evaluation of the managerial performances in the educational system}

In most European countries, the competent authorities responsible with education are the inspectorates, being responsible with schools' evaluation in the context of the scholar autonomy. The systems of inspection can be central or 
delegated. Since the end of 1990, in many countries, the criteria used to evaluate schools have been according to present standards.

To evaluate managerial performances in the Romanian pre-university educational system the evaluation grid method is applied which means to elaborate a list of criteria for each of this a scale of assessment being attached.

The stuff subject to the evaluation process is marked on the bases on score which reflects his performance level for each criterion taken separately.

Evaluation date sheet of the director's activity from the Romanian preuniversity education does not permit a relevant assessment of the directors of schools, letting enough room for subjective interpretations, suggesting that this system of evaluation has disadvantages:

- It does not offer clear information, detailed on performance criteria

- The assessment general criteria of the performance mentioned in the evaluation date sheet are general, there not being a breakdown in detail, fact which would better catch the director's activity.

- The present evaluation system does not offer clear clues regarding the why the activity takes place and the performances evaluation in time.

Another system of evaluation that can be used to evaluate school managers could be based on two documents:

- the individual evaluation sheet with criteria grouped according to the observed domain in the managerial activity. This sheet will be filled by both the manager and the assessor;

- the interview sheet, which is to be filled during the interview between the assessor and the school manager where to be mentioned the correlations with the individual evaluation sheet of the performances.

In France, the primary school principals evaluation is realized by the National Education Inspector and in secondary schools, the school director evaluation in realized by the Minister's representatives in regional plan (recteurs d'academie) and by the departmental directors from the Ministry (inspecteurs d'academie). The performances are grouped in for fields divided into sub-domains and the reportgrid is the evaluation instrument, where each competence is given a rating from unsatisfying to superior. After the self-evaluation of each competence domain, the director's commentaries or the supervisor's recommendations can be added, because the evaluation has two stages, like in Romania: self-evaluation and the superior authority's evaluation.

In the United States, in 2002, National Policy Board for Education Administration (NPBEA) published L'Educational Leadership Constituent Council (LECC) - standard accepted and used to employing, training and evaluation in schools from more than 20 states from the United States of America (AdamsRodgers and Johnston, 2008). From 1996 Interstate School Leaders Licence Consortium (ISLLC) published Standards for school leaders, guide for school directors' training. Each of the six standards of performance and main criteria (vision, organizational culture, management, community relations, ethics and social context) is described by the performance descriptors to which are associated 
examples of activities, attitudes that must operate through standard realization and performances which can be observed at an administrator which touch the standard. The scope of the evaluation process is to improve the performance and not to show incompetence.

\section{Conclusions}

In terms of competency - performance relationship there is a management system of the competence based on performance. Application of this system leads to achieving the vision, the mission, the objectives of the organization everything being possible due to the increase of the human resources thorough its distinct and unique skills augmentation. Enriching human capital optimizes other organizational resources, this working as a lever for the actual strengths of the organization (Kandula, 2006, p. 240).

Practice demonstrates undoubtedly that the performance, achieving high quality goals of an action, is possible only at high and corresponding level of competence. When the competence level is low, the performance is low, too.

But there are frequent situations when the level of the competence is high but the practical results are low. This phenomenon is more meaningful in the case of the managers who, through their weak performances, generate important losses of capacities (material, informational and human losses). In such cases something goes wrong, that means something is wrong in the organizational and management system requiring diagnosis by consulting and establishment of corrective measures, through interventions from outside. Other times definition of fasting and the profile manager and the competence evaluation are wrong and irrelevant.

For school, to have performance means:

1. Good and very good school results

2. Social results (social integration of the alumni, percentage of success at admissions)

3. Curricular material, means of education

4. Social education programs

Managerial function represents a practical professional activity for whose exercising specific, technical and relational knowledge and abilities are needed. In relation to other functions and professions, the managerial function/position has two characteristics:

- It exerts on other people, so, it is not a solitary profession

- It is learned both in school and in professional practice.

The manager self-formation is essential for the organization development. It is the path towards the organization performance. As managers work to become efficient they raise the performance level of all organization. In current conditions, the organization depends on the performance and the managerial results for it to exist and survive. But, the managerial efficiency can be obtained only having a certain level of knowledge.

Obtaining and having a certain level of knowledge is achieved by accumulation of information, by study, by learning and by practical experience. At 
present, management has a precise contour and the science and art of management can be leaned by anybody on condition that he has innate inclinations to apply everything he learns.

\section{References}

- Cojocaru, V., \& Slutu, L. (2007), Management educaţional, Cartea Moldovei, Chişinău, p. 9.

- Harshman, C. L. (2009), Decoding behavior to improve results: Using iWAM to unlock motivational and attitudinal patterns. The Institute for Work Attitude \& Motivation.

- Jackson, D. N. (2008), MAB-II Multidimensional Aptitude Battery adaptat de Dragoş Iliescu şi Florian Glinţa, Cluj-Napoca: Ed Sinapsis.

- Kandula, S. R. (2006), Performance Management: Strategies, Interventions, Drivers, PHI Learning, p. 240.

- Kiel, F. \& Lennick, D. (2005), Moral intelligence - Enhancing business performance and leadership success. Upper Saddle River, New Jersey: Pearson Education.

- Molan, V. (2005), O naţiune care se respectă are învăţământ de calitate, Actualitatea academică, an V, nr. 3, Bucureşti, p. 59.

- Nicolescu, O., et al. (1992), Management. Editura Didactică şi Pedagogică, R.A. Bucureşti, p. 301.

- Normand, R. (2006), L'école efficace ou l'horizon du monde comme laboratoire. Revue des sciences de l'éducation, 32, p. 54.

- Pâslaru, Vl., et al. (2005), Construcţie şi dezvoltare curriculară. Cadru teoretic, Chişinău, p. 7.

- Puchin, A.E. (2011), Calitatea în învătământ şi educaţie: perspectiva managementului economic, Teză de doctorat, Bucuresti, p. 134.

- Rutter, M. B., Maugham, P., Mortimore, J. \& Ouston, A. (1979), Fifteen thousand hours: secondary schools and their effect on children. Cambridge: Harvard University Press, p. 58.

- Sackney, L. (2007), History of the school effectiveness and improvement movement in Canada over the past 25 years International Handbook of School Effectiveness and Improvement, T. Townsend, p.170.

- Townsend, T. (2007), International Handbook of School Effectiveness and Improvement (vol. 17). Boca Raton, FL: Springer International Handbooks of Education, p. 43. 